\title{
GALERI OBAT TRADISIONAL DAN SPA
}

\author{
Anastasia Wijayaputri ${ }^{1)}$, Eduard Tjahjadi ${ }^{2)}$ \\ 1) Program Studi S1 Arsitektur, Fakultas Teknik, Universitas Tarumanagara, wijayaputri.anastasia@gmail.com \\ 2) Program Studi S1 Arsitektur, Fakultas Teknik, Universitas Tarumanagara, eduard.tjahjadi8@gmail.com
}

\begin{abstract}
Abstrak
Dalam buku Architectural Tourism - Building for Urban Travel Destinations oleh Jan Specht, dikatakan bahwa arsitektur memiliki di peran berbeda dalam pariwisata di perkotaan, yaitu sebagai arsitektur wisata (tourism architecture) dan wisata arsitektur (architectural tourism). Wisata arsitektur mengacu pada arsitektur sebagai daya tarik wisata. Menurut World Health Organization (WHO), masyarakat dunia saat ini memiliki kecenderungan untuk kembali ke alam (back to nature) dalam hal menjaga, memelihara dan meningkatkan derajat kesehatannya, dengan memanfaatkan pelayanan kesehatan tradisional yang salah satunya adalah pijat. Pijat sendiri sudah dikenal di Indonesia sejak berabad-abad lalu. Pijat merupakan pengobatan tradisional Indonesia yang dilakukan turun temurun berdasarkan warisan leluhur, tradisi dan budaya bangsa Indonesia. Selain dengan pijat tradisional, peningkatan kecantikan dan kesehatan juga dapat dilakukan melalui konsumsi obat tradisional, yang dikenal di Indonesia sebagai jamu. Dari hasil survei yang dilakukan oleh kementerian perdagangan, dapat dilihat bahwa masyarakat dan pemerintah sependapat bahwa jamu merupakan produk budaya bangsa Indonesia yang patut dilestarikan. Proyek ini sejalan dengan program Kementerian Perdagangan “Jamu Indonesia Maju 2020" untuk meningkatkan pasar jamu di Indonesia dan mewujudkan jamu brand Indonesia serta peningkatan bisnis Spa di Indonesia. Proyek ini diharapkan dapat menjadi wisata arsitektur di Jakarta yang dapat menarik turis maupun warga Jakarta, sebagai tempat rekreasi dan relaksasi yang dapat mengedukasi dan meningkatkan kecintaan mereka terhadap obat tradisional Indonesia.
\end{abstract}

Kata kunci: obat tradisional, spa ,wisata arsitektur.

\begin{abstract}
It is written in Architectural Tourism - Building for Urban Travel Destinations book by Jan Specht, that architecture has a different role in urban tourism, namely as tourism architecture and architectural tourism. Architectural tourism refers to architecture as a tourist attraction. According to the World Health Organization (WHO), the global community has a back to nature tendency in terms of maintaining and improving their health in traditional way, one of which is massage. Massage itself has been known in Indonesia for centuries. Massage is a traditional Indonesian medicine that has been carried out based on ancestral traditions and culture for the Indonesian. Aside from traditional massage, enhancing beauty and health can also be done through the consumption of traditional medicines, which are known in Indonesia as 'jamu'. The result of a survey conducted by the Ministry of Trade show that public and government recognize that jamu as one of the Indonesian culture that should be preserved. This project is in accordance with the Ministry of Trade's program "Jamu Indonesia Maju 2020 " to increase the herbal market in Indonesia and create Indonesian herbal medicine brands, as well as business improvement on SPA in Indonesia. This project is expected to be an architectural tourism in Jakarta that attract tourists and Jakarta citizens, as a place of recreation and relaxation that also educate them and increase their love towards Indonesian Traditional Medicine.
\end{abstract}

Keywords: architectural tourism, SPA, traditional medicine.

\section{PENDAHULUAN}

\section{Peningkatan Kepedulian Masyarakat Akan Kesehatan}

Menurut World Health Organization (WHO) setiap negara perlu mengangkat serta mengembangkan pengobatan tradisionalnya masing-masing. Saat ini, masyarakat dunia 
memiliki kecenderungan untuk kembali ke alam (back to nature) dalam hal menjaga, memelihara dan meningkatkan derajat kesehatannya, dengan memanfaatkan pelayanan kesehatan tradisional yang salah satunya adalah pijat.

Dikutip dari kementerian kesehatan, di Indonesia, pijat telah dikenal sejak berabad-abad yang lalu. Pijat merupakan pengobatan tradisional Indonesia yang dilakukan turun temurun berdasarkan warisan leluhur, tradisi dan budaya bangsa Indonesia. Metode pengobatan tradisional ini telah banyak digunakan sebelum adanya pelayanan kesehatan formal. Berbagai ragam etnis dan budaya di Indonesia, akan menggambarkan juga beragamnya cara pijat. Pijat saat ini sudah dikembangkan untuk meningkatkan kesehatan dan kebugaran.

Selain pijat, terdapat perawatan kecantikan dan kesehatan menggunakan air yaitu SPA. SPA (Solus Per Aqua) berasal dari bahasa latin yang berarti sehat melalui air. Peningkatan kepedulian masyarakat Indonesia terhadap kecantikan dan kebugaran terbukti dari maraknya bisnis SPA di Indonesia. Dikutip dari buku The Essence of Indonesia SPA, 'Jika dilihat dari ratarata pertumbuhan $25 \%$ per tahun industri spa di Indonesia mencapai pendapatan 1 triliun rupiah.' Hal ini menunjukkan bahwa SPA di Indonesia memiliki peluang bisnis yang besar. Kemajuan bisnis spa di Indonesia juga ditunjang oleh iklim tropis yang membuat Indonesia dapat menghasilkan minyak essensial asli Indonesia yang berkualitas.

\section{Jamu Sebagai Warisan Budaya Bangsa Indonesia}

Dalam era global sekarang ini, masyarakat memiliki kecenderungan untuk memahami kebudayaan di luar lingkungannya. Menurut James J. Spillane (2003) bahwa produk pariwisata budaya memiliki segmen pasar khusus yaitu para "knowledge workers" atau dalam istilah kepariwisataan disebut "mature tourist" atau wisatawan yang berpengalaman dimana mereka melakukan perjalanan atau kunjungan ke kawasan lain dengan tujuan tidak hanya bersifat rekreasi tetapi lebih bermotivasi untuk menimba pengalaman melalui keterlibatan langsung dengan aktivitas kehidupan dan tradisi serta budaya masyarakat lokal. Segmen wisatawan tersebut terdiri para lanjut usia atau pensiunan (retired) yang pada umumnya merupakan kelompok menengah ke atas dan berpendidikan yang mempunyai waktu luang untuk bepergian.

Jamu merupakan salah satu warisan budaya bangsa Indonesia yang sudah digunakan secara turun - temurun. Indonesia sebenarnya memiliki keunggulan dalam hal pengembangan obat tradisional atau jamu, karena memiliki 9.600 jenis tanaman obat yang dapat digunakan sebagai bahan dasar jamu. Selain itu, pemerintah juga telah menggolongkan tanaman obat yang merupakan bahan baku pembuatan jamu ke dalam sepuluh komoditas potensial untuk dikembangkan.

Karena jamu merupakan produk warisan budaya bangsa dan dapat berkontribusi besar bagi penciptaan lapangan pekerjaan domestik, maka sudah selayaknya tradisi minum jamu dilestarikan sekaligus menciptakan tradisi cinta terhadap produk asli Indonesia.

\section{Pandangan Masyarakat Terhadap Obat Tradisional}

Berikut terlampir paparan data terkait pandangan atau persepsi masyarakat mengenai jamu. Secara umum terlihat bahwa pandangan masyarakat mengenai jamu cukup baik karena mereka masih mempercayai jamu berkhasiat bagi kesehatan dan kecantikan, namun mereka masih ragu dan enggan untuk mengkonsumsi jamu karena beberapa alasan. Dengan memodernisasi jamu dan memberi edukasi kepada masyarakat tentang jamu, diharapkan tingkat kepercayaan masyarakat terhadap jamu Indonesia dapat ditingkatkan. 
Asosiasi Jamu sebagai Produk Ramuan Bahan Alam Asli Indonesia

\begin{tabular}{|c|c|c|c|c|}
\hline \multirow{2}{*}{\multicolumn{3}{|c|}{ Asosiasi }} & \multicolumn{2}{|c|}{ RESPONDEN } \\
\hline & & & \multirow{2}{*}{$\begin{array}{c}\text { Konsumen } \\
2 \%\end{array}$} & \multirow{2}{*}{$\begin{array}{c}\begin{array}{c}\text { Non } \\
\text { Konsumen }\end{array} \\
5 \%\end{array}$} \\
\hline \multirow{10}{*}{$\begin{array}{l}\text { Produk Ramuan } \\
\text { Bahan Alam Asli } \\
\text { Indonesia }\end{array}$} & \multicolumn{2}{|c|}{$\begin{array}{l}\text { Tidak setuju dan Sangat } \\
\text { tidak setuju }\end{array}$} & & \\
\hline & \multicolumn{2}{|c|}{\begin{tabular}{|l|} 
Netral/Ragu-ragu \\
\end{tabular}} & $3 \%$ & $7 \%$ \\
\hline & \multicolumn{2}{|c|}{ Setuju dan Sangat Setuju } & $95 \%$ & $88 \%$ \\
\hline & \multirow{7}{*}{$\begin{array}{l}\text { Nilai } \\
\text { Rerata }\end{array}$} & Jabodetabek & 4.35 & 4,13 \\
\hline & & Jawa Barat & 4,68 & 4,08 \\
\hline & & Jawa Tengah & 4,61 & 4.13 \\
\hline & & Jawa Timur & 4.32 & 4,12 \\
\hline & & Bali & 4,40 & 4,24 \\
\hline & & Sumatera Utara & 4.28 & 4.04 \\
\hline & & NASIONAL & 4,40 & 4,13 \\
\hline
\end{tabular}

Asosiasi Jamu sebagai Produk Budaya Bangsa Indonesia

\begin{tabular}{|c|c|c|c|c|}
\hline \multirow{2}{*}{\multicolumn{3}{|c|}{ Asosiasi }} & \multicolumn{2}{|c|}{ RESPONDEN } \\
\hline & & & Konsumen & $\begin{array}{c}\text { Non } \\
\text { Konsumen }\end{array}$ \\
\hline \multirow{10}{*}{$\begin{array}{l}\text { Produk Budaya } \\
\text { Bangsa Indonesia }\end{array}$} & \multicolumn{2}{|c|}{$\begin{array}{l}\text { Tidak setuju dan Sangat } \\
\text { tidak setuju } \\
\end{array}$} & $2 \%$ & $5 \%$ \\
\hline & \multicolumn{2}{|c|}{\begin{tabular}{|l|} 
Netral/Ragu-ragu \\
\end{tabular}} & $2 \%$ & $8 \%$ \\
\hline & \multicolumn{2}{|c|}{\begin{tabular}{|l} 
Setuju dan Sangat Setuju \\
\end{tabular}} & $96 \%$ & $87 \%$ \\
\hline & \multirow{7}{*}{$\begin{array}{l}\text { Nilai } \\
\text { Rerata }\end{array}$} & Jabodetabek & 4.31 & 4.13 \\
\hline & & \begin{tabular}{|l|} 
Jawa Barat \\
\end{tabular} & 4.72 & 3,92 \\
\hline & & Jawa Tengah & 4,43 & 4,03 \\
\hline & & Jawa Timur & 4.44 & 4,16 \\
\hline & & Bali & 4.36 & 4,08 \\
\hline & & Sumatera Utara & 4.24 & 4,00 \\
\hline & & NASIONAL & 4,38 & 4.08 \\
\hline
\end{tabular}

Gambar 1. Tabel Pandangan Masyarakat Terhadap Jamu Sumber: Badan Penelitian dan Pengembangan Perdagangan, Kementerian Perdagangan

\begin{tabular}{|c|c|c|c|c|c|c|c|c|c|}
\hline \multicolumn{5}{|c|}{ Signifikansi Atribut Khasiat bagi Kesehatan/Kecantikan dari Jamu/C } & \multirow{2}{*}{\multicolumn{5}{|c|}{ Jamu sebagai Obat Yang Dapat Menyembuhkan Atau Mengurangi Sakit }} \\
\hline \multirow{2}{*}{\multicolumn{3}{|c|}{ Signifikansi }} & PERSE & NTASE & & & & & \\
\hline & & & Konsumen & Non & \multirow{2}{*}{\multicolumn{3}{|c|}{ Asosiasi }} & RESP & DEN \\
\hline \multirow{11}{*}{$\begin{array}{l}\text { Kesan Kualitas } \\
\text { Produk Jamu/Obat: } \\
\text { Berkhasiat Bagi } \\
\text { Kesehatan/ } \\
\text { Kecantikan }\end{array}$} & \multirow{2}{*}{\multicolumn{2}{|c|}{$\begin{array}{l}\text { Tidak penting dan Sangat } \\
\text { tidak penting }\end{array}$}} & & Konsumen & & & & Konsumen & $\begin{array}{c}\text { Non } \\
\text { Konsumen }\end{array}$ \\
\hline & & & $7,29 \%$ & $6,07 \%$ & \multirow{10}{*}{$\begin{array}{l}\text { Jamu sebagai obat } \\
\text { yang dapat } \\
\text { menyembuhkan } \\
\text { atau mengurangi } \\
\text { sakit }\end{array}$} & \multicolumn{2}{|c|}{$\begin{array}{l}\text { Tidak setuju dan Sangat } \\
\text { tidak setuju }\end{array}$} & $4 \%$ & $11 \%$ \\
\hline & Penting d & Sangat Penting & $92,31 \%$ & $91,09 \%$ & & Netral/ & Ragu-ragu & $12 \%$ & $25 \%$ \\
\hline & \multirow{8}{*}{$\begin{array}{l}\text { Nilai } \\
\text { Rerata }\end{array}$} & Jabodetabek & 44,45 & 44,45 & & Setuju & lan Sangat Setuju & $84 \%$ & $64 \%$ \\
\hline & & Jawa Barat & 4,88 & 4,48 & & \multirow{7}{*}{$\begin{array}{l}\text { Nilai } \\
\text { Rerata }\end{array}$} & Jabodetabek & 4,11 & 3,68 \\
\hline & & Jawa Tengah & 4,09 & 4,00 & & & Jawa Barat & 4,08 & 3.28 \\
\hline & & Jawa Timur & 4,00 & 4,00 & & & Jawa Tengah & 3,87 & 3,30 \\
\hline & & Bali & 4,44 & 4,24 & & & Jawa Timur & 4,00 & 3,68 \\
\hline & & Sumatera Utara & 4,40 & 4,32 & & & Bali & 4,12 & 3,88 \\
\hline & & Usey & & 4,33 & & & Sumatera Utara & 4,08 & 3,38 \\
\hline & & NASIONAL & 4,40 & 4,33 & & & NASIONAL & 4,07 & 3,60 \\
\hline
\end{tabular}

Gambar 2. Tabel Tingkat Kepercayaan Masyarakat Terhadap Jamu Sumber: Badan Penelitian dan Pengembangan Perdagangan, Kementerian Perdagangan

Alasan Respouden Tidak Mengkensumsi Jamu

\begin{tabular}{|c|c|c|c|c|c|c|c|}
\hline \multirow{2}{*}{$\begin{array}{c}\text { Kepercayaan } \\
\text { Responden Non } \\
\text { Konsumen terhadap: }\end{array}$} & \multicolumn{7}{|c|}{ Persentase } \\
\hline & $\begin{array}{l}\text { Jabo- } \\
\text { deta- } \\
\text { bek: }\end{array}$ & $\begin{array}{l}\text { Jawa } \\
\text { Barat }\end{array}$ & $\begin{array}{c}\text { Jawa } \\
\text { Teagah }\end{array}$ & $\begin{array}{l}\text { Jawa } \\
\text { Timux }\end{array}$ & Bali & Susat & Nas \\
\hline - Kareua tidak terbiasa & $66,40 \%$ & $58,00 \%$ & $100,00 \%$ & $72,00 \%$ & $100,00 \%$ & $4,00 \%$ & $\pi, 400$ \\
\hline $\begin{array}{l}\text { - Tidak Mendapatkan } \\
\text { informasi yang jelas }\end{array}$ & $67,20 \%$ & $4,00 \%$ & $100,00 \%$ & $4,00 \%$. & 96,00\% & $6,00 \%$ & 72.200 \\
\hline - Tidak menyukainya & 522005 & 64,006 & $100,00 \%$ & $60,00 \%$ & $84,00 \%$ & $62.00 \%$ & $63, \pi 0$ \\
\hline $\begin{array}{l}\text { - Karena dosisuya yang } \\
\text { tidak jelas }\end{array}$ & $31.20 \%$ & $68.00 \%$ & 87,0046 & $36,00 \%$. & $6 s, 00 \%$ & $44,00 \%$ & $57,70 \%$ \\
\hline - Kareas rasanya tidak enak & $52,00 \%$ & $68,00 \%$ & 26,1096 & $64,00 \%$ & $24,00 \%$ & 63,000 & $57, \pi 0 \%$. \\
\hline $\begin{array}{l}\text { - Karena tradisi keluarga } \\
\text { tidak minum jams }\end{array}$ & $37,60 \%$ & $56,00 \%$ & 91,300 & As, $00 \%$. & $60,00 \%$ & $76,00 \%$ & 51,600 . \\
\hline $\begin{array}{l}\text { - Karena tidak jelas } \\
\text { kocaposisiaya }\end{array}$ & $41.60 \%$ & $68,00 \%$ & $87,00 \%$ & 40,004 . & $68.00 \%$ & $32,00 \%$ & $50,000$. \\
\hline $\begin{array}{l}\text { - Karena tingknangan sekitar } \\
\text { tidak minum jamu }\end{array}$ & $36,50 \%$ & 52,004 & 52,6046 & $40,00 \%$. & 6s,00\% & $40,00 \%$ & 46,400 \\
\hline $\begin{array}{l}\text { - Tidak pereaya pada } \\
\text { kemanguranaya }\end{array}$ & $36.00 \%$ & $6 n, 006$ & $13,00 \%$ & 28,000 . & 72,000 & $36,00 \%$ & 42,300 \\
\hline $\begin{array}{l}\text { Karena berbalaya bagi } \\
\text { kesebatas bila terlale } \\
\text { banyak mengkonsumsinya } \\
\text { (overdoais) }\end{array}$ & $46,40 \%$ & $55.00 \%$ & $0.00 \%$ & $52,00 \%$. & $48,00 \%$ & $28.00 \%$ & 41.9006 \\
\hline $\begin{array}{l}\text { - Bentukaya tidak praktis } \\
\text { dan tidak ayaman }\end{array}$ & $26,40 \%$ & $44,00 \%$ & 0.0046 & 36,004 . & 76,004 & $32.00 \%$ & 32,300 . \\
\hline $\begin{array}{l}\text { - Karena tidak percaya pada } \\
\text { promosi di media massa }\end{array}$ & $29.60 \%$ & 44,004 & $0,00 \%$ & $36,00 \%$. & $60,00 \%$ & $24,00 \%$ & 31,300 \\
\hline $\begin{array}{l}\text { - Karena pengalaman pabir } \\
\text { masa lafu terkait jamus }\end{array}$ & $27.20 \%$ & $20,00 \%$ & 26,104 & $40,00 \%$. & $4,00 \%$ & $16.00 \%$ & 28.200 . \\
\hline $\begin{array}{l}\text { - Karena sulit diperoleb di } \\
\text { lisplasegan sekitar }\end{array}$ & $14,40 \%$ & $24,00 \%$ & $0.00 \%$ & $12,00 \%$. & $60,00 *$ & $12,00 \%$ & 18,104 \\
\hline - Karena harfanya mahal & 2.8006 & $12,00 \%$ & $0,00 \%$ & $20,00 \%$ & $46,00 \%$ & $8.00 \%$ & $13,30 \%$ \\
\hline
\end{tabular}

Sumber: Data primer (diolah)

Gambar 3. Tabel Alasan Responden Tidak Mengkonsumsi Jamu

Sumber: Badan Penelitian dan Pengembangan Perdagangan, Kementerian Perdagangan 
Tujuan proyek ini adalah meningkatkan kecintaan masyarakat terhadap obat tradisional dan SPA tradisional sebagai warisan budaya bangsa yang patut untuk dilestarikan, melalui program yang dikelola oleh swasta dengan memanfaatkan potensi pasar jamu dan SPA di Indonesia.

Berdasarkan uraian pada latar belakang, maka masalah yang akan dibahas pada penulisan ini, yaitu:

a. Bagaimana proyek yang bertujuan edukatif dan meningkatkan kecintaan terhadap warisan budaya lokal ini dapat berjalan diiringi dengan kegiatan komersial yang berguna bagi kelangsungan proyek.

b. Bagaimana menyatukan dua program utama yaitu galeri yang lebih diperuntukan bagi turis dan SPA yang lebih diperuntukan bagi warga Jakarta, dapat berjalan beriringan dan saling menunjang.

c. Bagaimana memperluas segmentasi pengunjung dari proyek yang lebih diminati oleh 'mature tourist' dan golongan ekonomi menengah ke atas.

d. Bagaimana menangani luas lahan di perkotaan yang relatif sempit dan terbatas untuk berkebun tanaman obat.

\section{KAJIAN LITERATUR}

\section{Pariwisata Arsitektur di Kota Metropolitan}

Dalam buku Architectural Tourism - Building for Urban Travel Destinations oleh Jan Specht, dikatakan bahwa arsitektur memiliki di peran berbeda dalam pariwisata di perkotaan, yaitu sebagai arsitektur wisata (tourism architecture) dan wisata arsitektur (architectural Tourism). Arsitektur wisata dapat didefinisikan sebagai berbagai fungsi arsitektur dalam konteks pariwisata. Sedangkan, wisata arsitektur mengacu pada arsitektur sebagai daya tarik wisata. Mayoritas dari turis mengunjungi sebuah kota bukan untuk satu atraksi atau daya tarik saja, melainkan untuk sekelompok campuran dari beberapa daya tarik. Campuran daya tarik ini dapat tersebar di beberapa distrik dan mencakup beberapa jenis dan fungsi. Arsitektur yang ikonik dapat digunakan untuk revitalisasi sebuah kawasan yang sudah ada, atau bisa juga digunakan sebagai landasan untuk memulai dan memperkenalkan keseluruhan dari area pengembangan baru. Dalam hal wisata arsitektur, tema adalah aspek penting dalam memberikan keseluruhan pengalaman pengunjung. Contohnya Disneyland, sebagai sebuah taman hiburan memiliki tema yang membuatnya berbeda dari taman hiburan yang lain.

\section{Tipologi Sebagai Metode Dalam Merancang}

Tipologi adalah kajian tentang tipe. Konsep tipe Quatremere de Quincy yang memahami tipe sebagai asal usul dari sesuatu yang mengandung unsur-unsur yang tidak dapat dikurangi lagi sehingga dapat bericiri. Tipe, dengan mengandung unsur-unsur dasar saja, lebih longgar bergerak karena dari situ berkembang macam-macam model.

Dalam kajian tipologis, sebuah objek arsitektur yang hadir perlu kita amati unsur-unsur pembentuknya. Bangunan adalah kumpulan unsur-unsur yang membentuknya. Untuk mengerti bagaimana unsur-unsur itu disusun oleh perancangnya, kita perlu mempelajari satupersatu unsur penyusunnya.

Dalam menganalisa sebuah bangunan, pertama-tama kita perlu melihat cara penulis menanggapi lahan / tapak. Kemudian kita masukan satu-persatu unsur pembentuk bangunan tersebut, seperti kolom, dinding, bukaan, lantai, atap dan lain sebagainya. Dari situ kita dapat menganalisis dari segi denah, potongan, dan tampak.

Melalui kajian tipologi kita mendapat perbandingan antar bangunan proyek sejenis dan mengetahui unsur-unsur yang mendasar sebagai pembentuk bangunan tersebut. Unsur-unsur mendasar tersebut yang nantinya kita jadikan sebagai panduan dalam merancang. 


\section{Tipologi Sebagai Metode Dalam Merancang}

Arsitektur hijau adalah suatu pendekatan perencanaan bangunan yang berusaha untuk meminimalkan berbagai pengaruh buruk yang membahayakan kesehatan manusia dan lingkungan. Aplikasi arsitektur hijau akan menciptakan suatu bentuk arsitektur yang berkelanjutan (sustainable architecture).

Istilah arsitektur berkelanjutan atau sustainable architecture menjadi sangat populer ketika mantan Perdana Menteri Norwegia GH Bruntland memformulasikan pengertian Pembangunan Berkelanjutan (sustainable development) pada tahun 1987 sebagai pembangunan yang dapat memenuhi kebutuhan manusia masa kini tanpa mengorbankan potensi generasi mendatang untuk memenuhi kebutuhan mereka sendiri.

\section{METODE}

Dalam proses penulisan Tugas Akhir ini, menggunakan metode pembahasan dengan 3 tahap:

a. Tahap pengumpulan data.

b. Pengumpulan data dilakukan dengan cara:

- Melakukan survey lapangan dan observasi.

- Melakukan studi pustaka.

- Melakukan studi literatur pada proyek sejenis.

c. Tahap analisa.

d. Metode yang dilakukan dalam melakukan analisa adalah:

- Induksi, yaitu menarik kesimpulan dari fakta yang ada.

- Komparasi, yaitu menganalisis melalui data yang sudah dikumpulkan melalui survey dan studi literatur.

e. Tahap sintesis.

f. Tahap ini merupakan tahap perumusan konsep, dari hasil analisa.

\section{DISKUSI DAN HASIL}

\section{Ide Perencanaan}

\section{Sarana Edukasi Sekaligus Komersial}

Jika diamati kondisi sarana edukasi di Jakarta seperti museum, jauh berbeda dengan kondisi museum di luar negri. Mayoritas museum di Jakarta berada dalam kondisi yang kurang baik dan tidak jarang dalam kondisi tak terawat. Hal ini disebabkan oleh berbagai faktor, salah satunya kurangnya biaya pemeliharaan. Sehingga galeri dipilih sebagai program utama sarana edukasi tentang obat tradisional karena di dalam galeri dapat terjadi transaksi jual beli yang hasilnya dapat digunakan untuk pemeliharaan banguan. Fungsi komersial seperti market, restoran dan workshop di tambahkan sebagai sarana komersil yang dapat menambah keuntungan proyek.

\section{Dua Program Utama}

Spa dipilih sebagai program komersil yang diharapkan dapat membantu pembiayaan pengelolaan proyek ini. Bagi turis Galeri Obat Tradisional akan menjadi tujuan utama, sedangkan bagi warga Jakarta yang akan menjadi tujuan adalah Spa. Maka kedua program ini harus sama besarnya dan saling melengkapi. Sehingga lokasi proyek selain harus berdekatan dengan pusat kegiatan warga Jakarta seperti pusat perbelanjaan.

\section{Perluasan Segmentasi Pengunjung}

Karena obat tradisional cenderung lebih diminati oleh 'mature tourist' atau turis yang tertarik dengan tradisi dan kebudayaan masyarakat lokal dan pengunjung yang berumur menengah ke atas, maka diperlukan program pendukung yang mampu menarik anak muda untuk berkunjung. Sehingga ditambahkan café yang dirancang menarik dan instagramable yang menyajikan live music bergaya anak muda pada hari-hari tertentu. 


\section{Keterbatasan Luas Lahan untuk Berkebun di Perkotaan}

Lahan di perkotaan yang relatif sempit dan terbatas, menimbulkan permasalahan untuk bercocok tanam. Vertikultur merupakan cara bercocok tanam yang dilakukan dengan menempatkan media tanam dalam wadah yang tersusun vertikal. Hal ini dilakukan sebagai alternatif bagi masyarakat yang tinggal di perkotaan dengan lahan sempit. Sehingga beberapa tanaman obat pada proyek ini dapat ditanam secara vertikal untuk menjadi contoh bagi pengunjung yang ingin menerapkannya di rumah.

\section{Program Kegiatan}

Galeri Obat Tradisional ini memiliki 2 program utama yaitu SPA yang lebih ditargetkan untuk penduduk Jakarta dan Galeri Obat Tradisional yang ditargetkan untuk wisatawan dan memiliki program tambahan sebagai pelengkap. Program tambahan berkaitan adalah Taman Tanaman Obat, sedangkan restoran dan café memiliki keterkaitan tidak langsung dengan program utama. Deskripsi program-program tersebut akan dijelaskan dan dijabarkan sebagai berikut:

a. SPA (Golongan Spa Tirta 3) dengan desain $80 \%$ unsur budaya Indonesia.

- Memiliki ruang perawatan hydrotherapy spa yang terpisah dengan ruang perawatan lainnya.

- Dua buah ruang sauna untuk laki-laki dan perempuan.

- Memiliki 2 tipe ruang perawatan terapi pijat, yaitu yang kapasitas satu orang dan yang kapasitas dua orang.

- Ruang perawatan rambut dan kulit kepala.

- Ruang perawatan kaki dan tangan.

- Ruang olah fisik yang digunakan untuk latihan pernafasan, latihan kelenturan (stretching) serta yoga.

- Ruang makan dan minum, sekaligus sebagai ruang tunggu sebelum pengunjung memasuki ruang perawatan.

- Ruang penunjang seperti: ruang penerimaan tamu yang dilengkapi dengan lobby, ruang bilas, ruang ganti dan toilet.

- Ruang penunjang pengelola seperti: ruang kantor, ruang linen, dan gudang.

b. Galeri Obat Tradisional

- Memiliki ruang pameran yang berfungsi sebagai pusat informasi mengenai pembuatan obat tradisional (mulai dari bahan bakunya, proses pengolahannya sampai pemanfaatannya).

- Pusat perbelanjaan obat tradisional.

- Ruang workshop, ruangan ini digunakan untuk workshop dan demo proses pembuatan obat dan lulur secara tradisional.

- Ruang penunjang pengelola seperti : ruang kantor, gudang.

c. Taman Tanaman Obat

- Ruang luar yang berfungsi sebagai sarana edukasi bagi pengunjung tentang tanaman obat, dari cara penanaman dan perawatannya.

- Memiliki ampiteater yang dapat dimanfaatkan untuk pertunjukan seni dan tempat bermain mainan tradisional untuk anak-anak.

d. Restoran, Cafe yang Dilengkapi Dapur

e. Ruang-ruang pendukung yang dapat digunakan oleh seluruh program diatas seperti: ruang ganti dan istirahat karyawan, ruang petugas keamanan, toilet karyawan, ruang ibadah karyawan, tempat penampungan sampah, ruang genset dan fasilitas servis lainnya. 


\section{Lokasi}

Dari permasalahan yang telah disebutkan di atas, penjabaran luasan ruang serta studi preseden, maka dapat ditentukan kriteria tapak yang sesuai dengan program proyek, yaitu :

- Berada di daerah second layer Jakarta dengan banyak kegiatan penjualan obat tradisional dimana warganya masih banyak yang meminati obat tradisional.

- Dekat dengan objek-objek wisata di Jakarta dan pusat kegiatan warga Jakarta.

- Dekat dengan tempat favorit anak muda di Jakarta agar mampu menarik anak muda untuk datang.

- Akses yang mudah baik dengan kendaraan pribadi maupun transportasi publik, diusahakan dekat dengan stasiun MRT atau LRT di masa mendatang.

- Memiliki KDB dan KLB yang tidak terlalu tinggi dengan KB 2-6 lantai.

Kota administrasi Jakarta Barat dipilih karena jumlah UKM Obat Tradisional terbanyak berada disini. Dari seluruh kecamatan di Jakarta Barat, kecamatan Kebon Jeruk dipilih karena daerahnya yang masih memungkinkan untuk dibuat bangunan wisata serta merupakan kecamatan dengan UKM Obat Tradisional terbanyak setelah Cengkareng dan Grogol.

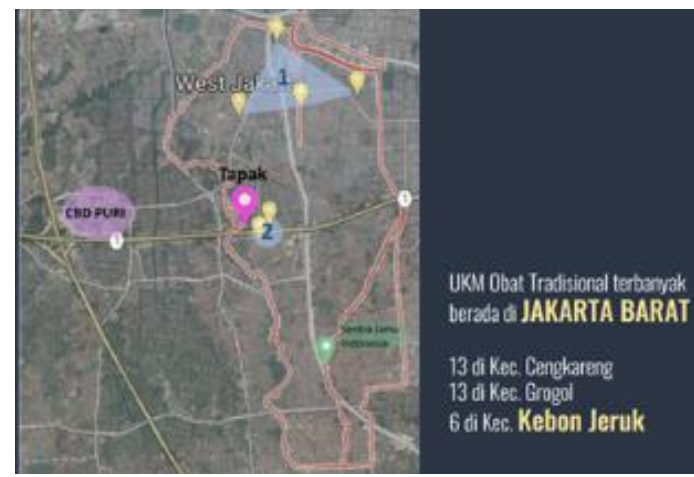

Gambar 4. Penyebaran UKM Obat Tradisional di Kebon Jeruk Sumber: Olahan Penulis, 2018

Di kecamatan Kebon Jeruk, penyebaran UKM Obat Tradisional terbagi pada 2 titik, titik nomor 1 merupakan daerah yang didominasi oleh pabrik dan ruko. Titik nomor 2 dipilih karena aksesnya yang mudah, dekat dengan jalan Tol dan CBD Puri. Berada di second layer Jakarta, kecamatan Kebon Jeruk, kota administrasi Jakarta Barat yang daerahnya didominasi oleh perkantoran dan permukiman. Kecamatan Kebon Jeruk nantinya akan dilewati oleh jalur MRT koridor Barat-Timur. Tapak berada di Jl. Kedoya Raya, Kecamatan Kebon Jeruk, Jakarta Barat. Tapak berada diantara CBD Puri dan Superblok Central Park, daerah sekitar tapak didominasi ruko dan kantor serta permukiman baik perumahan maupun bangunan apartemen yang sudah terbangun maupun yang belum (rencana).

Gambar 5. Keberadaan Proyek Terhadap Kota Jakarta Sumber: Olahan Penulis, 2018 


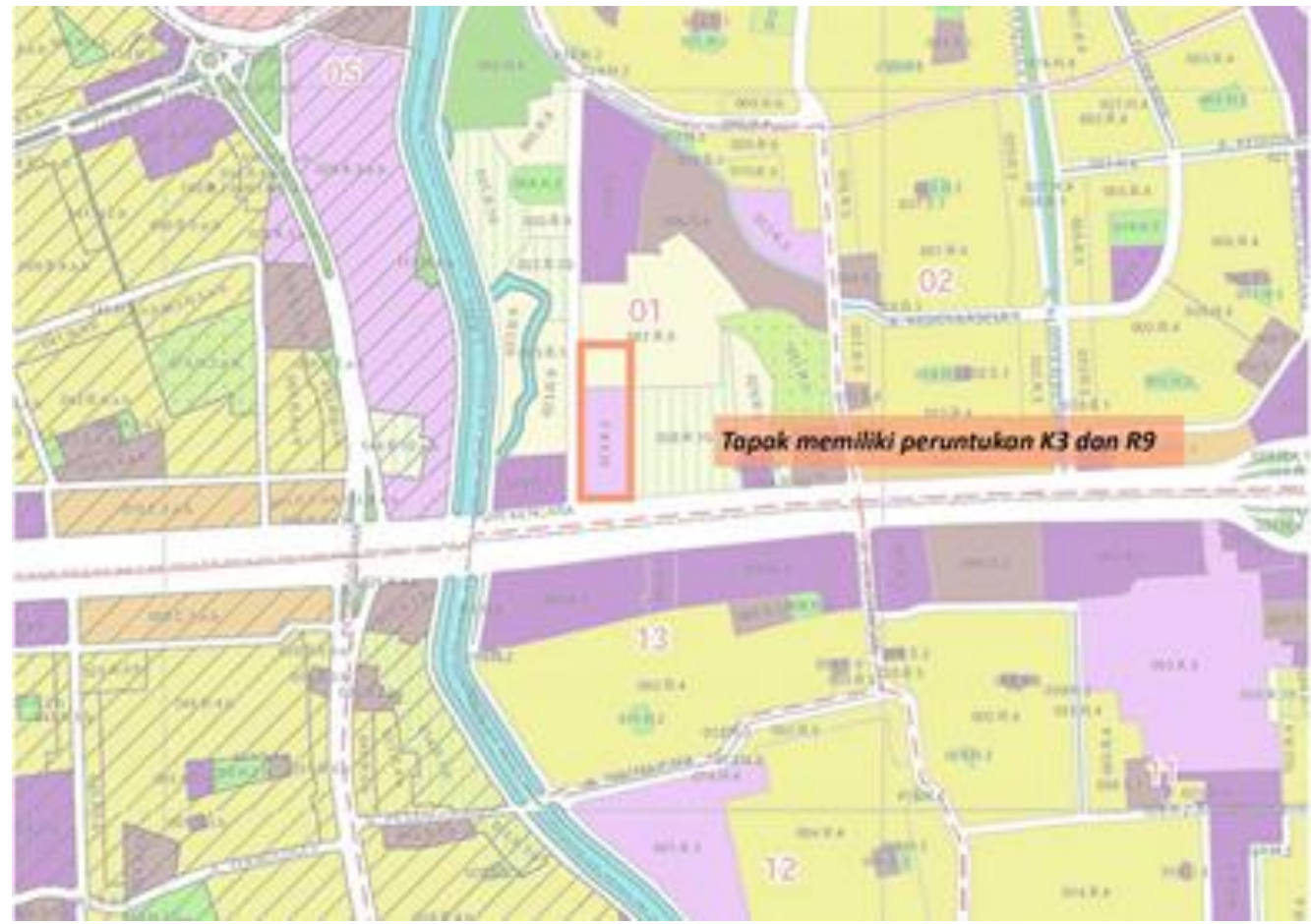

Gambar 6. Rencana Kota di Daerah Tapak

Sumber: Olahan Penulis, 2018

Daerah sekitar tapak memiliki peruntukan perkantoran dan permukiman. Daerah yang berbatasan langsung dengan tapak sampai dengan radius 200 meter dari tapak, memiliki peruntukan permukiman dengan KDB dan KLB tinggi.

Gambar 7. Kondisi Tapak

Sumber: Olahan Penulis, 2018

\section{Analisa Tapak}

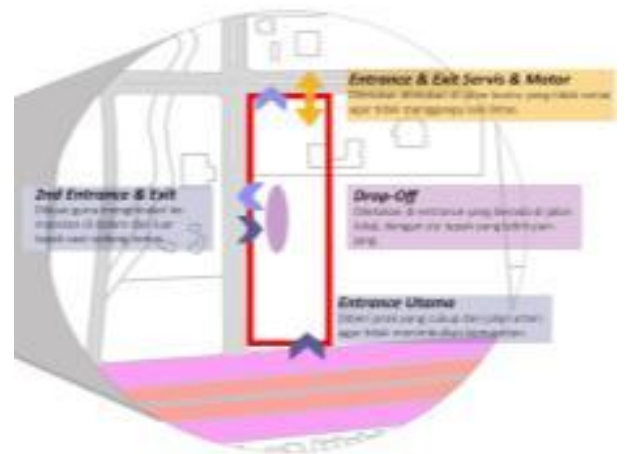

Gambar 8. Analisa Pedestrian dan Kendaraan

Sumber: Olahan Penulis, 2018 

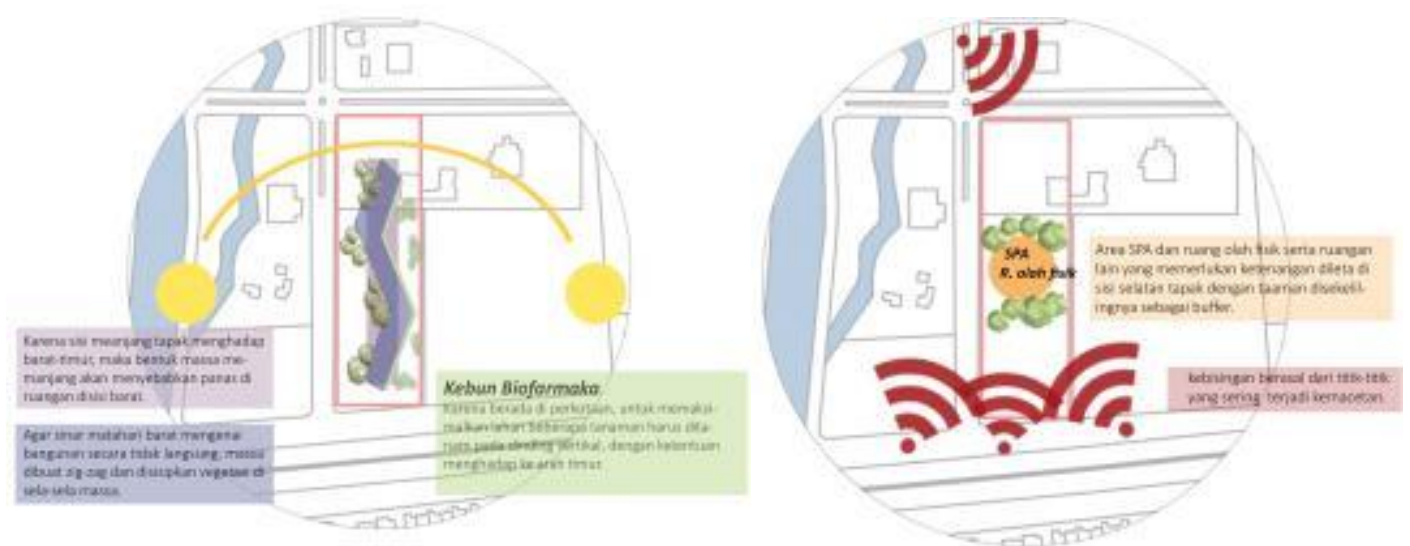

Gambar 9. Analisa Matahari dan Kebisingan Sumber: Olahan Penulis, 2018

\section{Konsep dan Strategi Desain}

Berangkat dari SPA (Solus Per Aqua) dalam bahasa latin yang berarti perawatan dengan air, maka konsep yang diangkat adalah air. Gerakan air yang dinamis dituangkan dalam bangunan yang dapat terlihat pada bentuk massa bangunan serta pola pergerakan pengunjung yang dibuat berliku-liku (Gambar 10).

Sirkulasi pengunjung baik dari basement maupun dari luar tapak diarahkan menuju lantai dasar yang merupakan area publik. Untuk menuju lantai atas, hanya dapat dilalui dengan lift dan tangga yang berada di tengah yang juga merupakan titik pusat penyebaran pengunjung nantinya di lantai 2, hal ini bertujuan agar pengunjung dapat melihat-lihat dan merasakan suasana di dalam site terlebih dahulu sebelum akhirnya masuk ke area galeri maupun area SPA (Gambar 11).

Terdapat satu buah lift servis yang berhenti di lantai basement (tempat loading dock), lantai dasar dan lantai dua. Lantai dasar dan lantai dua bersifat publik dimana terdapat market, restoran, cafe dan retail yang banyak memerlukan aktivitas servis (Gambar 11). Terdapat tiga titik tangga evakuasi yang tersebar pada massa bangunan yang dibuat menerus agar pengunjung tidak kehilangan orientasi saat terjadi keadaan darurat (Gambar 11). 
Gambar 10. Konsep Bangunan

Sumber: Olahan Penulis, 2018

Gambar 11. Konsep Sirkulasi

Sumber: Olahan Penulis, 2018

Fasad bangunan dibuat dinamis, dengan rangka pipa baja berdiameter 2 inch yang terkesan menyambung, menyelimuti bangunan. Rangka ini ditumbuhi tanaman merambat dan tanaman obat yang dapat menjadi solusi bagi penanaman tanaman obat di kahan kota yang relatif sempit.

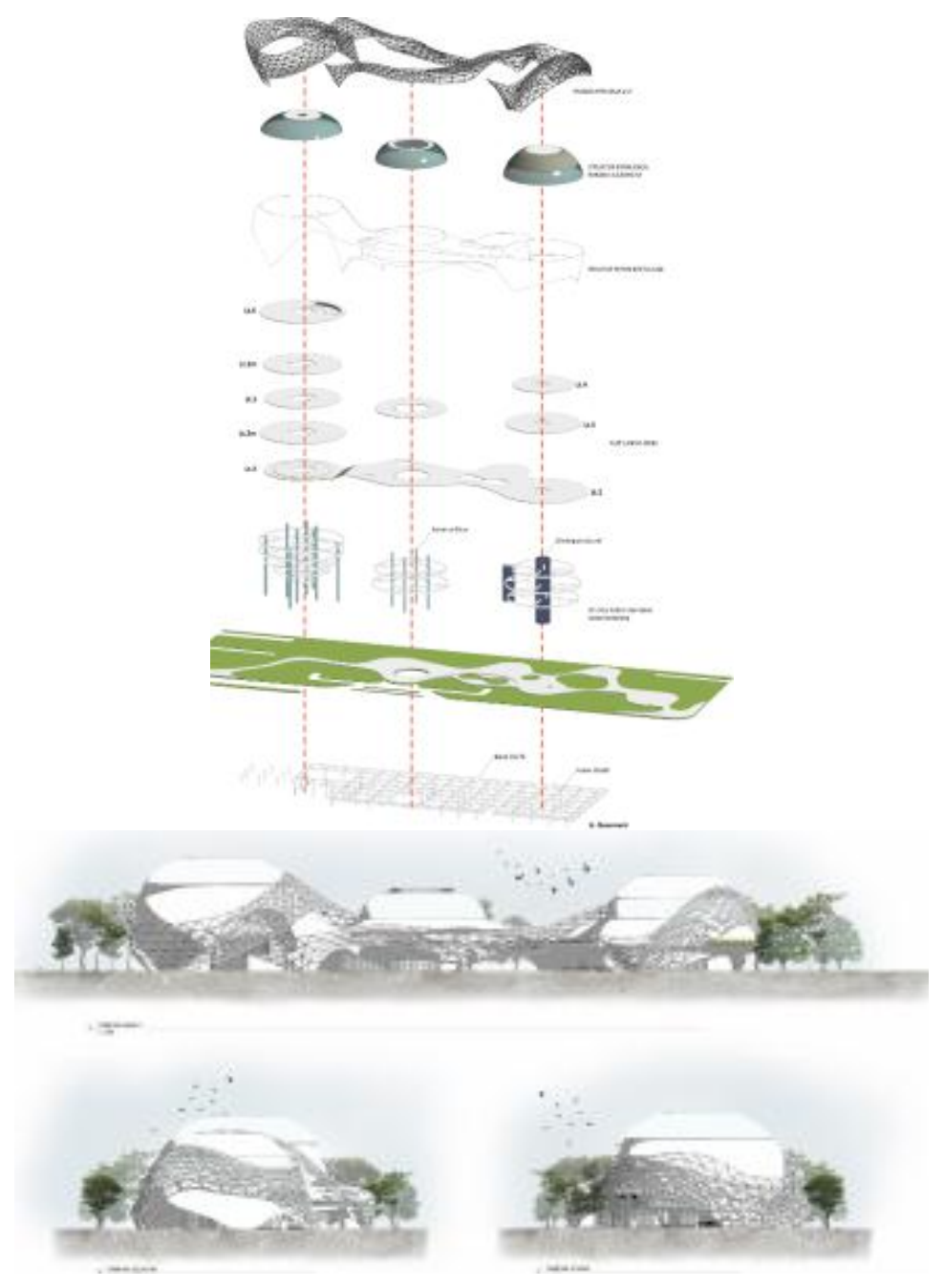

Gambar 12. Struktur dan Fasade Bangunan

Sumber: Olahan Penulis, 2018

\section{KESIMPULAN DAN SARAN}

Dari data-data yang sudah terkumpul dapat disimpulkan bahwa, sekarang ini masyarakat mulai kembali menyadari pentingnya kesehatan, dengan berkembangnya tren back to nature, 
obat-obatan dengan bahan-bahan alami seperti obat tradisional kembali digemari. Pengobatan tradisional seperti pijat dan SPA menjadi peluang bisnis yang menjanjikan.

Galeri Obat Tradisional dan SPA ini, menjadi sarana edukasi sekaligus komersial sehingga dapat dikelola oleh swasta dan mampu menunjang biaya perawatan dan pengelolaannya sendiri. Proyek ini diharapkan dapat mempopulerkan jamu dan meningkatkan kecintaan masyarakat terhadap jamu serta memperkenalkan jamu kepada turis asing khususnya 'mature tourist'. Bagi warga Jakarta, proyek ini diharapkan dapat menjadi sarana kesehatan melalui pengobatan tradisional untuk meningkatkan dan menjaga derajat kesehatan mereka.

\section{UCAPAN TERIMA KASIH}

Penulis mengucapkan terima kasih kepada Tuhan yang Maha Esa, Dosen Pembimbing Utama dan Dosen Pembimbing lainnya yang telah membimbing serta memberikan banyak masukan sehingga penulis dapat menyelesaikan artikel ilmiah ini.

\section{REFERENSI}

Specht, Jan. (2014), Architectural Tourism: Building for Urban Travel Destination, Springer Gabler, Germany.

Maciocco, Giovanni and Serreli, Silvia. (2009), Enhancing the City: New Perspectives for Tourism and Leisure, Springer Dordrecht Heidelberg London, New York.

Jumarani, Louise. (2013), The Essence of Indonesia SPA, Gramedia Pustaka Utama, Indonesia. Tjahjono, Gunawan, Metode Perancangan Suatu Pengantar untuk Arsitek dan Perancang. https://www.theguardian.com/artanddesign/2017/oct/01/bilbao-effect-frank-gehryguggenheim-global-craze

Kajian Potensi Pengembangan Pasar Jamu oleh Pusat Penelitian dan Pengembangan Perdagangan Dalam Negeri, Badan Penelitian dan Pengembangan Perdagangan, Kementerian Perdagangan, 2009.

Peraturan Menteri Kesehatan Republik Indonesia Nomor: 003/Menkes/Per/2010 tentang Saintifikasi Jamu dalam Penelitian Berbasis Pelayanan Kesehatan.

Peraturan Menteri Pariwisata dan Ekonomi Kreatif Republik Indonesia Nomor 24 Tahun 2014 Tentang Standar Usaha Spa. 